University of Nebraska - Lincoln

DigitalCommons@University of Nebraska - Lincoln

2008

Detection of the Superoxide Radical Anion Using Various Alkanethiol Monolayers and Immobilized Cytochrome $c$

Xiaojun J. Chen

Alan C. West

Donald M. Cropek

Scott Banta

Follow this and additional works at: https://digitalcommons.unl.edu/usarmyresearch

Part of the Operations Research, Systems Engineering and Industrial Engineering Commons

Chen, Xiaojun J.; West, Alan C.; Cropek, Donald M.; and Banta, Scott, "Detection of the Superoxide Radical Anion Using Various Alkanethiol Monolayers and Immobilized Cytochrome c" (2008). US Army Research. 10.

https://digitalcommons.unl.edu/usarmyresearch/10

This Article is brought to you for free and open access by the U.S. Department of Defense at DigitalCommons@University of Nebraska - Lincoln. It has been accepted for inclusion in US Army Research by an authorized administrator of DigitalCommons@University of Nebraska - Lincoln. 


\title{
Detection of the Superoxide Radical Anion Using Various Alkanethiol Monolayers and Immobilized Cytochrome c
}

\author{
Xiaojun J. Chen, ${ }^{\dagger, \ddagger, \S}$ Alan C. West, ${ }^{\dagger}$ Donald M. Cropek, ${ }^{\ddagger}$ and Scott Banta*,† \\ Department of Chemical Engineering, Columbia University, New York, New York, 10027, and U.S. Army Engineer \\ Research and Development Center, Construction Engineering Research Laboratory (CERL), Champaign, Illinois 61826
}

The superoxide radical anion (SO) is a critical biomarker for monitoring cellular stress responses. Electrochemical SO biosensors are frequently constructed through the covalent immobilization of cytochrome $c$ (Cyt c) onto selfassembled monolayers (SAMs); however, a detailed comparison of these systems as well as configuration influence on SO detection is needed to enable robust applications. Two reaction pathways, oxidation of SO by the SAMmodified gold electrode or electron transfer through a protein and monolayer relay, may be involved during the electrochemical detection of SO with Cyt $c$, depending on the SAM that is used. Although electrodes with SAMs alone can exhibit a high sensitivity and low limit of detection (LOD) for the SO, they can suffer from a strong response to the presence of interferents such as hydrogen peroxide and ascorbic acid. Electrodes with immobilized Cyt $c$ show decreased sensitivity, but exhibit better selectivity and resistance to fouling in complex media. Considering the trade-offs between sensitivity, selectivity, and LOD for SO detection, a bioelectrode made with Cyt c immobilized on dithiobis(succinimidyl)propionate (DTSP) appears to be the most suitable configuration. In phosphate buffer, the DTSP/Cyt $c$ electrode has a sensitivity of $410 \mathrm{nA} \mu \mathrm{M}^{-1} \mathrm{~cm}^{-2}$ and an LOD for SO of $73 \mathrm{nM}$. Results are also presented for the detection of SO in a complex tissue culture media (MEM) with and without serum, and the sensitivity of the DTSP/Cyt $c$ in MEM in the absence of serum increased to $640 \mathrm{nA} \mu \mathrm{M}^{-1} \mathrm{~cm}^{-2}$. By measuring SO with a DTSP/Cyt $c$ electrode before and after the addition of a bolus of the superoxide dismutase (SOD) enzyme, the specificity of the SOD enzyme can be combined with the sensitivity of Cyt $c$ system.

Interest in developing methods for detecting the concentration of the superoxide radical anion $\left(\mathrm{O}_{2}{ }^{\circ}\right)$ in physiologically relevant environments has been increasing, as it is involved in both normal physiology and disease pathology. ${ }^{1-5}$ Superoxide radical anion

\footnotetext{
* To whom correspondence should be addressed. E-mail: sbanta@ cheme.columbia.edu. Phone: (212) 854-7531Fax: (212) 854-3054.

$\dagger$ Columbia University.

* CERL.

$\$$ Present Address: Institute of Bioengineering and Nanotechnology, Singapore.

(1) Droge, W. Physiol. Rev. 2002, 82, 47-95.

(2) Valko, M.; Leibfritz, D.; Moncol, J.; Cronin, M. T.; Mazur, M.; Telser, J. Int. J. Biochem. Cell Biol. 2007, 39, 44-84.
}

(SO) is an important reactive oxygen species (ROS) deployed by the immune system to defend against viral or bacterial attack. For example, SO can be generated during the oxidative burst of phagocytic cells such as activated macrophages or neutrophils to kill invasive microorganisms. ${ }^{6} \mathrm{SO}$ is also generated by nonphagocytic cells, and it is involved in signal transduction and regulation. Most cell types can generate a small oxidative burst upon stimulation by growth factors, cytokines, and hormones, and it is thought that the ROS can serve as secondary messengers. ${ }^{2}$ Oxidative stress is also involved in various pathological conditions including cancer, cardiovascular disease, rheumatoid arthritis, neurological disorders, ischemia/reperfusion, diabetes, and aging., ${ }^{1,2}$ Robust and reliable detection of SO could improve our understanding of the pathology and physiology of clinical conditions that involve ROS. ${ }^{7-9}$ However, SO undergoes rapid self and enzymatic disproportionation under normal physiological conditions (a half-life in the range of milliseconds to seconds at neutral $\mathrm{pH}$ values), leading to low peak concentrations $\left(\sim 1 \times 10^{-11} \mathrm{M}\right)$. Thus, selective, sensitive, and fast-response detection methods are needed to quantify the SO concentrations in a variety of in vitro and in vivo systems.

Over the past decades, several detection methods have been developed for SO measurement. ${ }^{10,11}$ Electrochemical methods for SO quantification are of particular interest because they can be easily integrated into portable analytical devices. The incorporation of proteins onto bioelectrodes enables the creation of systems that can exploit highly evolved biological recognition and catalysis in order to increase specificity. ${ }^{12}$ The two main proteins used in the construction of SO biosensors are cytochrome $c$ (Cyt $c$ ) and superoxide dismutase (SOD) ${ }^{13} \mathrm{Cyt} c$ is a ubiquitous protein that is involved in shuttling electrons during oxidative phosphorylation, but it is not itself an enzyme specific for the conversion of SO. SOD is an enzyme, and it evolved specifically for the rapid

(3) Afanas'ev, I. B. Mol. Biotechnol. 2007, 37, 2-4.

(4) Fridovich, I. Annu. Rev. Pharmacol. Toxicol. 1983, 23, 239-257.

(5) Mates, J. M. Toxicology 2000, 153, 83-104.

(6) Babior, B. M. Am. J. Med. 2000, 109, 33-44.

(7) Fabian, R. H.; Kent, T. A. Free Radical Biol. Med. 1999, 26, 355-361.

(8) Liu, D.; Sybert, T. E.; Qian, H.; Liu, J. Free Radical Biol. Med. 1998, 25, 298-304.

(9) Fabian, R. H.; Perez-Polo, J. R.; Kent, T. A. J. Neurosci. Res. 2000, 60, 795-803.

(10) Pontie, M.; Bedioui, F. Analusis 1999, 27, 564-570.

(11) Tian, Y.; Mao, L. Q.; Ohsaka, T. Curr. Anal. Chem. 2006, 2, 51-58.

(12) Newman, J. D.; Setford, S. J. Mol. Biotechnol. 2006, 32, 249-268.

(13) Lisdat, F.; Scheller, F. W. Anal. Lett. 2000, 33, 1-16. 
dismutation of SO as part of the cellular antioxidant defense system. In fact, this enzyme is considered to display perfect catalytic behavior as the turnover number is so high that the enzyme approaches mass transfer limitation in solution. ${ }^{14,15}$

Although many research groups have reported SO biosensors with immobilized Cyt $c$ or SOD, the results can be difficult to compare as various immobilization strategies, protein sources, and performance criteria have been employed. For example, Cyt $c$-based biosensors have been created using a variety of alkanethiol self-assembling monolayers (SAMs) such as the 11-mercaptoundecanoic acid (MUA)/11-mercaptoundecanol (MU) mixed monolayer, ${ }^{16}$ the 3,3 -dithiobissulfosuccinimidylpropionate monolayer ${ }^{17}$ and the 3-mercaptopropionic acid (MPA)/3-mercaptoethanol (MP) mixed monolayer. ${ }^{18}$ SOD-based biosensors have been created using various members of the SOD family adsorbed or immobilized on cysteine- or MPA-modified electrodes. ${ }^{19-23}$ Recently, a SOD sensor was made with a mutant enzyme that was engineered to bind to electrodes. ${ }^{24}$ Despite these successes, fundamental data comparing the performance of these systems are lacking.

To be useful for the study of cell physiology, SO biosensors must be functional in an environmental milieu of potential interferents. In this work, we have explored the responses of gold electrodes modified with various alkanethiol SAMs in the presence of SO generated by the xanthine and xanthine oxidase (XOD) reaction. The monolayers were also modified with Cyt $c$, and calibration curves in the absence of interferents were determined. The responses of several of the electrodes to relevant interferents, including tissue culture media, are also reported. The dithiobis(succinimidyl)propionate (DTSP)/Cyt $c$ bioelectrode appears to be the most suitable design, displaying a high sensitivity and low limit of detection (LOD). This sensor can also be operated before and after the introduction of a bolus of SOD to confirm response is due to $\mathrm{SO}$, and this detection scheme utilizes the high sensitivity of Cyt $c$ coupled with the specificity of the SOD enzymatic reaction, which may be optimal for a portable analytical device.

\section{EXPERIMENTAL DETAILS}

Reagents. Cyt $c$ from bovine heart, $\mathrm{Cu} / \mathrm{Zn} \mathrm{SOD}$ from bovine erythrocytes (SOD, EC 1.15.1.1), XOD (EC 1.17.3.2) from bovine milk, xanthine, uric acid, L-ascorbic acid, Eagle's Minimum Essential Media (MEM), dimethyl sulfoxide (DMSO), MPA, MP, MUA, MU, 1-propanethiol, cysteamine, urate, ethanol, and hy-

(14) Bertini, I.; Mangani, S.; Viezzoli, M. S. Adv. Inorg. Chem. 1998, 45, 127250.

(15) Culotta, V. C.; Yang, M.; O’Halloran, T. V. Biochim. Biophys. Acta: Mol. Cell Res. 2006, 1763, 747-758.

(16) Ge, B.; Lisdat, F. Anal. Chim. Acta 2002, 454, 53-64.

(17) Chang, S. C.; Pereira-Rodrigues, N.; Henderson, J. R.; Cole, A.; Bedioui, F.; McNeil, C. J. Biosens. Bioelectron. 2005, 21, 917-922.

(18) Gobi, K. V.; Mizutani, F. J. Electroanal. Chem. 2000, 484, 172-181.

(19) Ohsaka, T.; Tian, Y.; Shioda, M.; Kasahara, S.; Okajima, T. Chem. Commun. 2002, 990-991.

(20) Tian, Y.; Ariga, T.; Takashima, N.; Okajima, T.; Mao, L. Q.; Ohsaka, T. Electrochem. Commun. 2004, 6, 609-614.

(21) Tian, Y.; Mao, L.; Okajima, T.; Ohsaka, T. Anal. Chem. 2002, 74, 24282434.

(22) Tian, Y.; Mao, L. Q.; Okajima, T.; Ohsaka, T. Anal. Chem. 2004, 76, 41624168.

(23) Tian, Y.; Mao, L. Q.; Okajima, T.; Ohsaka, T. Biosen. Bioelectron. 2005, 21, 557-564.

(24) Beissenhirtz, M. K.; Scheller, F. W.; Viezzoli, M. S.; Lisdat, F. Anal. Chem. 2006, 78, 928-935. drogen peroxide (30\%) were from Sigma Aldrich (St. Louis, MO). DTSP, $N$-hydroxysuccinimide (NHS), and 1-ethyl-3-(3-dimethylaminopropyl) carbodiimide hydrochloride (EDC) were purchased from Pierce (Rockford, IL). All chemicals were of analytical grade and used as received. The $25 \mathrm{mM}$ sodium phosphate buffer (PB) was prepared with a $25 \mathrm{mM}$ sodium dihydrogen phosphate solution, adjusted to a $\mathrm{pH}$ value of 7.4 with $1 \mathrm{~N} \mathrm{NaOH}$. Stock solutions of $10 \mathrm{mM} \mathrm{H}_{2} \mathrm{O}_{2}$ and $1 \mathrm{mM}$ L-ascorbic acid were prepared in PB. A $1 \mathrm{mM}$ xanthine stock solution was freshly prepared before each experiment. Briefly, $7.6 \mathrm{mg}$ of xanthine was dissolved in 1 $\mathrm{mL}$ of $1 \mathrm{~N} \mathrm{NaOH}$, which was diluted to $50 \mathrm{~mL}$ using $25 \mathrm{mM}$ sodium dihydrogen phosphate. The $\mathrm{pH}$ of this xanthine solution was then adjusted with concentrated $\mathrm{NaOH}$ to 7.4. All aqueous solutions were prepared with $18.2 \mathrm{M} \Omega$ Millipore water.

Electrode Preparation. Gold electrodes with a diameter of $3 \mathrm{~mm}$ (Metrohm Ion Analysis, Brinkmann Instruments, Westbury, NY) were polished with emery paper (No. 2000) and then successively polished with $1-\mu \mathrm{m}$ diamond paste and $0.3-\mu \mathrm{m}$ alumina paste on a polishing microcloth, followed by ultrasonication in ethanol and deionized water each for 10 min to remove adsorbed alumina particles. The electrodes were then electrochemically cycled in $0.1 \mathrm{M} \mathrm{H}_{2} \mathrm{SO}_{4}$ between -0.2 and $1.5 \mathrm{~V}$ at a scan rate of $10 \mathrm{~V} / \mathrm{s}$ until a typical cyclic voltammogram of a clean gold surface was obtained ( $\sim 1000$ cycles).

The alkanethiol electrodes (propanethiol, MP, MPA, MPA:MP, and MUA:MU) were prepared by immersing cleaned gold electrodes in a $10 \mathrm{mM}$ alkanethiol solution in ethanol for $24 \mathrm{~h}$ at room temperature to allow the self-assembled monolayer formation on the gold surface. The mole ratio of MPA to MP (or MUA to MU) was 1:3. The DTSP monolayer electrode was prepared by immersing the gold electrode in a $10 \mathrm{mM}$ DTSP solution in DMSO for $2 \mathrm{~h}$ at room temperature, and the cysteamine monolayer electrode was formed in a $10 \mathrm{mM}$ cysteamine solution in deionized water for $1 \mathrm{~h}$ at room temperature. The carboxyl terminals on the MPA, MPA:MP. and MUA:MU monolayers were activated by incubating in $2 \mathrm{mM}$ EDC and $5 \mathrm{mM}$ NHS for $30 \mathrm{~min}$ at room temperature. The DTSP monolayer contains an aminereactive NHS ester so that no activation is needed. ${ }^{25}$ Finally, the Cyt $c$ electrodes were constructed by incubating the modified activated gold electrodes in $20 \mu \mathrm{L}$ of $2 \mathrm{mg} / \mathrm{mL}$ Cyt $c$ (prepared in $25 \mathrm{mM} \mathrm{PB}$ ) solution for $24 \mathrm{~h}$ at $4{ }^{\circ} \mathrm{C}$ to covalently link the protein to the monolayer. After the covalent bonding, the Cyt $c$ electrodes were named as MPA/Cyt $c$, MPA:MP/Cyt $c$, MUA:MU/Cyt $c$, and DTSP/Cyt $c$ electrodes. These electrodes were stored at $4{ }^{\circ} \mathrm{C}$ when not in use.

Apparatus and Electrochemical Measurements. All electrochemical measurements were performed in a three-electrode cell with 2-mL volume using Autolab PGSTAT100 (Eco Chemie, The Netherlands). The Cyt $c$ electrodes (or monolayer electrodes) and a platinum wire were used as the working and counter electrodes, respectively. During electrochemical measurements, the potentials applied to the working electrode were referred to an $\mathrm{Ag} / \mathrm{AgCl}(1 \mathrm{M} \mathrm{KCl})$ reference electrode. The amperometric responses of the bioelectrodes to $\mathrm{SO}$ and interferents were performed at various potentials ( $\mathrm{vs} \mathrm{Ag} / \mathrm{AgCl}, 1 \mathrm{M} \mathrm{KCl}$ ) in $\mathrm{PB}$ normally at a rotation rate of $1000 \mathrm{rpm}$ (Pine Instruments, Raleigh,

(25) Darder, M.; Takada, K.; Pariente, F.; Lorenzo, E.; Abruna, H. D. Anal. Chem. 1999, 71, 5530-5537. 
$\mathrm{NC})$. SO was generated by the enzymatic reaction of xanthine and xanthine oxidase. Concentrations of SO were varied by adding $50 \mu \mathrm{M}$ xanthine into $25 \mathrm{mM} \mathrm{PB} \mathrm{(pH} \mathrm{7.4)} \mathrm{containing} \mathrm{varying}$ amounts of XOD.

Determination of Enzymatic SO Generation Rate. The generation rate of SO in the xanthine-XOD system was determined spectrophotometrically (SpectraMax M2, Molecular Devices, Sunnyvale, $\mathrm{CA}$ ) in $800 \mu \mathrm{L}$ of $25 \mathrm{mM}$ oxygen-saturated $\mathrm{PB}$ containing $166 \mu \mathrm{M}$ oxidized Cyt $c$ (ferricytochrome $c$ ), $200 \mu \mathrm{M}$ xanthine, and XOD. The XOD activities in the buffer ranged from 5 to $100 \mathrm{mU} / \mathrm{mL}$. In the presence of ferricytochrome $c$, the SO generation rate is proportional to the reduction of ferricytochrome $c$ to ferrocytochrome $c$ by SO. The enzymatic SO generation rate can be determined from the slope of the kinetic curve recorded during the production of ferrocytochrome $c$ at $550 \mathrm{~nm}$ with an extinction coefficient of $28 \mathrm{mM}^{-1} \mathrm{~cm}^{-1}$ (datum provided by Sigma) for $1 \mathrm{~min}$. All experiments were performed at room temperature $\left(22 \pm 1^{\circ} \mathrm{C}\right)$.

\section{RESULTS AND DISCUSSION}

In Situ Generation of SO by the Xanthine and Xanthine Oxidase System. Because of the short half-life time of SO, the xanthine-XOD system was used to generate steady-state SO concentrations in neutral solutions. SO is continuously created by the enzymatic reaction (eq 1) and it quickly undergoes selfdisproportionation (eq 2).

$$
\begin{gathered}
\text { xanthine }+2 \mathrm{O}_{2}+\mathrm{H}_{2} \mathrm{O} \stackrel{k_{1}}{\rightarrow} \text { urate }+2 \mathrm{O}_{2}^{--}+2 \mathrm{H}^{+} \\
2 \mathrm{O}_{2}^{--}+2 \mathrm{H}^{+} \stackrel{k_{2}}{\longrightarrow} \mathrm{O}_{2}+\mathrm{H}_{2} \mathrm{O}_{2}
\end{gathered}
$$

When xanthine and oxygen are both saturating, the generation rate of SO (eq 1) can be simplified to be proportional to the XOD activity: $v_{1}=2 k_{1}[\mathrm{XOD}]$. The self-disproportionation rate of SO (eq 2) can be described as $v_{2}=2 k_{2}\left[\mathrm{O}_{2}^{--}\right]^{2}$. By combining the reactions, the accumulation rate of SO in the xanthine-XOD system can be expressed as

$$
\frac{\mathrm{d}\left[\mathrm{O}_{2}^{--}\right]}{\mathrm{d} t}=v_{1}-v_{2}=2 k_{1}[\mathrm{XOD}]-2 k_{2}\left[\mathrm{O}_{2}^{\cdot-}\right]^{2}
$$

Under steady state, $\mathrm{d}\left[\mathrm{O}_{2}^{--}\right] / \mathrm{d} t=0$. Thus,

$$
\left[\mathrm{O}_{2}^{--}\right]_{\text {steady }}=\sqrt{\frac{k_{1}}{k_{2}}[\mathrm{XOD}]}
$$

The generation rate of the $\mathrm{SO}$ was determined experimentally by continuously recording the absorbance of ferrocytochrome $c$ in solution. Figure $1 \mathrm{~A}$ shows the kinetics of ferricytochrome $c$ reduction to ferrocytochrome $c$ as a function of XOD activity with an initial xanthine concentration of $50 \mu \mathrm{M}$. The generation rate of SO, $k_{1}$, is proportional to the slope of the kinetic reaction curve. Thus, the relationship between XOD activity and the SO generation rate can be established from the ferrocytochrome $c$ kinetics. Together with the spontaneous disproportionation rate of $\mathrm{SO}, k_{2}$,
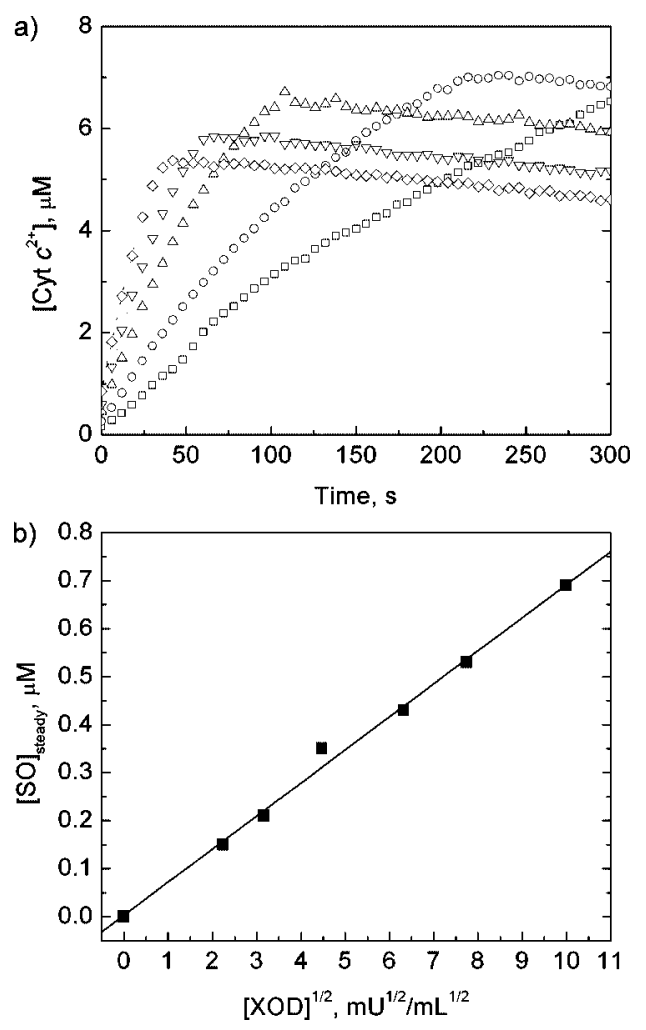

Figure 1. In situ generation of $S O$ by xanthine and xanthine oxidase system. (A) Kinetics of ferricytochrome $c$ reduction activity with an initial xanthine concentration of $50 \mu \mathrm{M}$. The initial XOD concentrations were $10(\square), 20(\bigcirc), 40(\Delta), 60(\nabla)$, and $100 \mathrm{mU} / \mathrm{mL}(\diamond)$. (B) A calibration curve for the steady-state concentration of $\mathrm{SO}$ as a function of the square root of XOD activity with excess xanthine in solution.

which is given as $2.3 \times 10^{5} \mathrm{M}^{-1} \mathrm{~s}^{-1}$ at $\mathrm{pH} 7.5,{ }^{26}$ the steady-state SO concentration as a function of XOD activity can be obtained. This calibration curve is shown in Figure 1B, where the SO concentration increases linearly with the square root of the XOD concentration. A similar approach has been used for SO calibration when hypoxanthine is used as a substrate. ${ }^{16}$

Amperometric Responses of the Monolayer Electrodes to SO in Phosphate Buffer. Several alkanethiol SAMs have been used in the construction of SO biosensors, but their response to SO without immobilized protein are rarely reported. Therefore, the amperometric responses of neat alkanethiol SAMs with the same 3-carbon chain length but different functional termini were investigated. Figure 2 shows the effect of different functional end groups on the amperometric responses to the presence of SO, while the response of the bare gold electrode can be found in the Supporting Information. In all cases, the addition of SOD caused the current to return to baseline (data not shown), verifying that $\mathrm{SO}$ was being measured and not the addition of xanthine or XOD. It was found that the different termini of the alkanethiols have a significant influence on the amperometric responses to SO. Among the four functional end groups, the SAM with the $\mathrm{NH}_{2}$ terminus had the strongest response to SO and the SAM with the $\mathrm{COOH}$ terminus exhibited the weakest response. Specifically, the 3-carbon chain length monolayers with functional termini of $\mathrm{COOH}$ (MPA), $\mathrm{CH}_{3}$ (propanethiol), $\mathrm{OH}$ (MP), or $\mathrm{NH}_{2}$ (cysteam-

(26) Behar, D.; Czapski, G.; Rabani, J.; Dorfman, L. M.; Schwarz, H. A. J. Phys. Chem. 1970, 74, 3209-3213. 


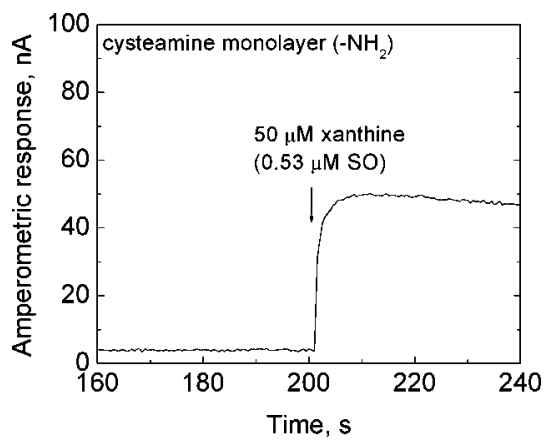

a)
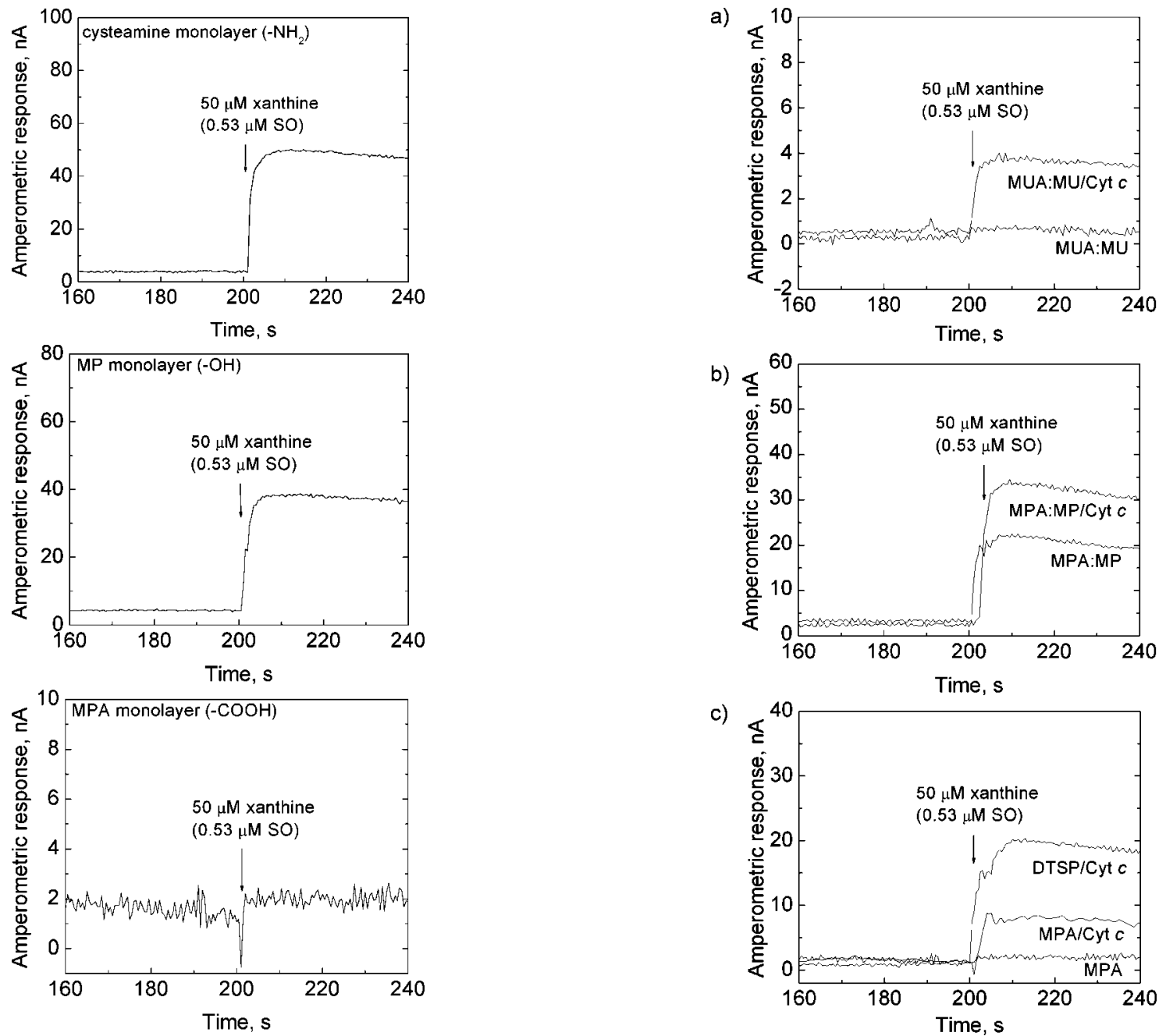

c)
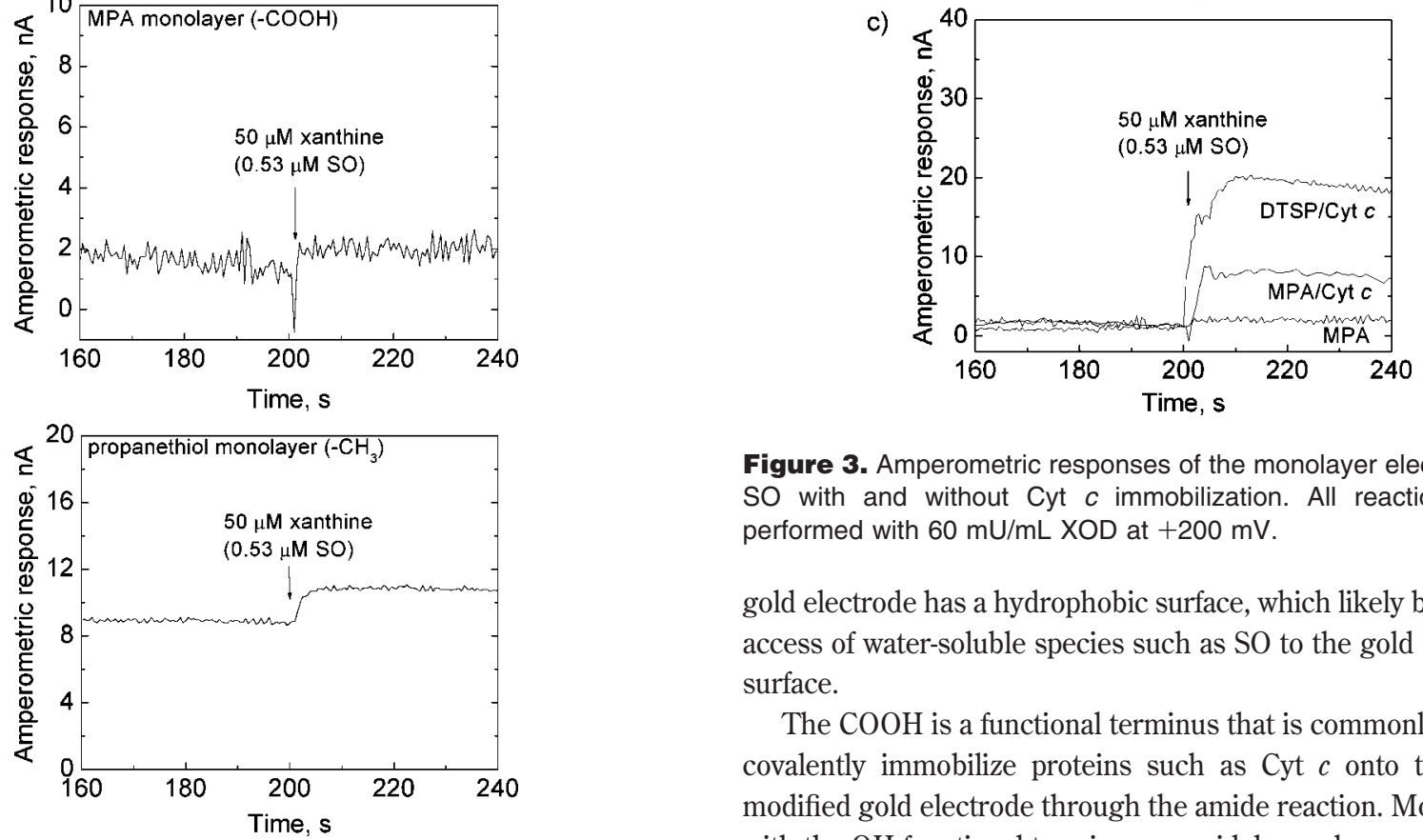

Figure 2. Effect of the unmodified alkanethiol SAM terminus chemistry on the amperometric responses to SO. All reactions were performed with $60 \mathrm{mU} / \mathrm{mL}$ XOD at $+200 \mathrm{mV}$.

ine) exhibit amperometric responses of $0.5,2.1,34$, and $46 \mathrm{nA}$, respectively, upon the addition of $50 \mu \mathrm{M}$ xanthine in the presence of $60 \mathrm{mU} / \mathrm{mL}$ XOD. The $\mathrm{NH}_{2}$ terminus is positively charged at $\mathrm{pH}$ 7.4, which may attract the negatively charged SO radical to the gold electrode surface, leading to the strong response of the $\mathrm{HS}\left(\mathrm{CH}_{2}\right)_{3} \mathrm{NH}_{2}$-modified gold electrode to SO. Conversely, the weak response of the $\mathrm{HS}\left(\mathrm{CH}_{2}\right)_{3} \mathrm{COOH}$-modified gold electrode to SO may be due to repulsion by the negatively charged carboxyl group at $\mathrm{pH}$ 7.4. The $\mathrm{HS}\left(\mathrm{CH}_{2}\right)_{3} \mathrm{OH}$-modified gold electrode has a neutral surface, which may enable the SO to access the gold surface for direct electrooxidation. The $\mathrm{HS}\left(\mathrm{CH}_{2}\right)_{3} \mathrm{CH}_{3}$-modified

Figure 3. Amperometric responses of the monolayer electrodes to SO with and without Cyt $c$ immobilization. All reactions were performed with $60 \mathrm{mU} / \mathrm{mL}$ XOD at $+200 \mathrm{mV}$.

gold electrode has a hydrophobic surface, which likely blocks the access of water-soluble species such as SO to the gold electrode surface.

The $\mathrm{COOH}$ is a functional terminus that is commonly used to covalently immobilize proteins such as Cyt $c$ onto the SAMmodified gold electrode through the amide reaction. Monolayers with the $\mathrm{OH}$ functional terminus are widely used as a spacers on the modified gold surface for protein immobilization. ${ }^{16,18}$ Thus, only the alkanethiol SAMs with carboxyl and hydroxyl terminals are reported on in detail for the protein immobilization experiments.

Amperometric Responses of the Cyt $c$ Electrodes to SO in Phosphate Buffer. The amperometric responses of the monolayer-modified gold electrode to SO with and without Cyt $c$ immobilization are presented in Figure 3. Cyt $c$ was covalently immobilized on four kinds of monolayers: an MUA:MU mixed monolayer, an MPA:MP mixed monolayer, an MPA monolayer, and the DTSP monolayer. SO biosensors constructed by immobilizing Cyt $c$ on mixed monolayer SAMs (both MUA:MU and MPA:MP) have been reported to have higher responses than on the MUA and MPA monolayers alone. ${ }^{16,18}$ However, as shown in Figure 2, the monolayer with hydroxyl group itself has a strong response to SO. Therefore, the high current responses previously 
observed in the literature can be due to the oxidation of SO both by the monolayer and by the Cyt $c$ protein. The results in Figure 3 indicate that the MPA:MP monolayer electrode has a strong response of $19.5 \mathrm{nA}$ to $0.53 \mu \mathrm{M} \mathrm{SO}$, while the response of the MUA:MU monolayer electrode to $0.53 \mu \mathrm{M}$ SO is negligible. Generally, the long carbon chain alkanethiols result in better passivation of the gold surface after modification. ${ }^{27}$ This effect is likely the main reason for the different amperometric responses to SO for the gold electrode modified with MUA:MU and MPA: MP mixed monolayers.

As shown in Figure 3, after immobilizing Cyt $c$ on the SAMs, the bioelectrodes showed higher amperometric responses to 0.53 $\mu \mathrm{M}$ SO than was observed for the neat monolayer electrodes. The improvement of the Cyt $c$ electrode over the monolayer electrode is especially obvious for the Cyt $c$ electrodes prepared on MUA: MU mixed monolayer (Figure 3A) and MPA monolayer (Figure $3 \mathrm{C})$. Because negligible amperometric responses to $\mathrm{SO}$ were observed for MUA:MU and MPA monolayer electrodes, the incremental increase in current upon the production of SO in the solution can be confidently attributed to the direct electron transfer from the immobilized Cyt $c$ to the gold electrode through the monolayer relay. In contrast, both the MPA:MP/Cyt $c$ electrode and the MPA:MP electrodes exhibit a large response to the SO (Figure 3B) and thus the benefits of Cyt $c$ incorporation are minimal. DTSP is an amino-reactive NHS ester cross-linker, which, after cleavage of the disulfide bond, has same structure as the NHS-activated MPA upon assembly on the gold electrode. Experiments with the neat DTSP monolayer cannot be performed, as it would react and immobilize the XOD enzyme. Although the two electrodes should be similar, as shown in Figure 3C, the DTSP/ Cyt $c$ electrode exhibited much higher response to SO than the $\mathrm{MPA} / \mathrm{Cyt} c$ electrode, which may be due to a higher efficiency of the Cyt $c$ covalent immobilization on the DTSP monolayer surface.

Based on the results presented in Figures 2 and 3, two possible reaction pathways likely occur during the electrochemical detection of SO, i.e., electron transfer through Cyt $c$ and the monolayer relay (pathway I) and oxidation of superoxide by the SAMmodified gold electrode independent of the Cyt $c$ (pathway II). Reaction pathway I is the main pathway for the electrochemical detection of SO on the MUA:MU/Cyt $c$, MPA/Cyt $c$, and DTSP/ Cyt $c$ electrodes, while reaction pathway II is responsible for the behavior of SO at bare gold electrodes and those modified with neat SAMs, such as MP, propanethiol, cysteamine, and MPA:MP. For the MPA:MP/Cyt $c$ electrode, both reaction pathways I and II likely contribute to the total amperometric response to the SO.

Figure 4 shows calibration curves (with no background subtraction) of five different electrode configurations to varying SO concentrations in $25 \mathrm{mM} \mathrm{PB}(\mathrm{pH} 7.4)$ at $+200 \mathrm{mV}$, obtained by varying the $\mathrm{XOD}$ activity in the buffer solution. The error bars are based on four independently prepared electrodes. Reproducibility of a single electrode, when exposed multiple times to the SO radical, was also good (not shown). The LOD and sensitivity of each electrode were obtained from Figure 4 and summarized in Table 1. The LOD is rigorously defined as the baseline measurement (intercept) plus three times the standard deviation of the baseline signal in the absence of SO, converted into units of superoxide concentration. ${ }^{28}$ It was found that the MP monolayer

(27) Strong, L.; Whitesides, G. M. Langmuir 1988, 4, 546-558.

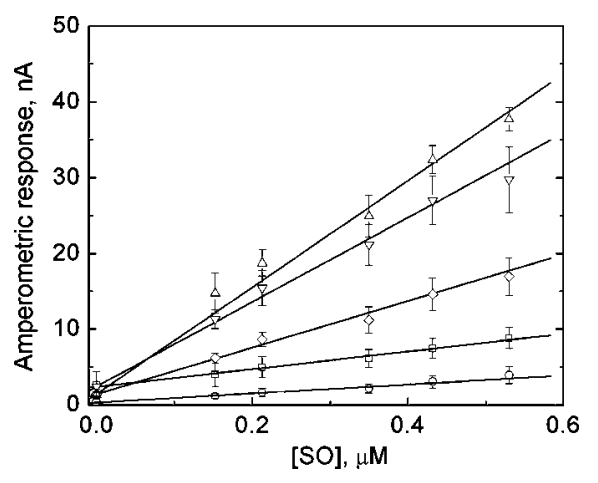

Figure 4. Calibration curves of 5 different electrodes for $\mathrm{SO}$ in 25 $\mathrm{mM}$ PB $(\mathrm{pH} 7.4)$ at $+200 \mathrm{mV}$ vs $\mathrm{Ag} / \mathrm{AgCl}$ reference. The different electrodes used were MUA:MU/Cyt $c(O)$, MPA/Cyt $c(\square)$, DTSP/Cyt $c(\diamond)$, MPA:MP/Cyt $c(\nabla)$, and neat MP $(\Delta)$.

\section{Table 1. LOD and Sensitivity of Different Electrodes for so Detection ${ }^{a}$}

\begin{tabular}{lcc}
$\quad$ electrodes & LOD $(\mu \mathrm{M})$ & sensitivity $\left(\mathrm{nA} \mu \mathrm{M}^{-1} \mathrm{~m}^{-2}\right)$ \\
MUA:MU/Cyt $c$ & 0.24 & 93 \\
DTSP/Cyt $c$ & 0.073 & 410 \\
MPA/Cyt $c$ & 0.68 & 160 \\
MPA:MP/Cyt $c$ & 0.065 & 740 \\
MP monolayer & 0.038 & 940 \\
\multicolumn{2}{c}{} \\
${ }^{a} n=5$ for all measurements.
\end{tabular}

electrode has the highest sensitivity (940 $\mathrm{nA} \mu \mathrm{M}^{-1} \mathrm{~cm}^{-2}$ ) and the lowest LOD $(0.038 \mu \mathrm{M})$ for the detection of SO in $25 \mathrm{mM} \mathrm{PB}$ $(\mathrm{pH}$ 7.4) at $+200 \mathrm{mV}$. As shown in Figure $3 \mathrm{~A}$ and $\mathrm{C}$, the MUA: MU and MPA monolayers exhibit good passivation for the electrochemical detection of SO. Attachment of Cyt $c$ to these monolayers activates pathway I although performance metrics are not as good as the MP monolayer. The sensitivity for the MUA: MU/Cyt $c$ electrode (93 nA $\mu \mathrm{M}^{-1} \mathrm{~cm}^{-2}$ ) was found to be $\sim 3$-fold better than what was previously reported for this system using a gold needle disk electrode $\left(27.6 \mathrm{nA} \mu \mathrm{M}^{-1} \mathrm{~cm}^{-2}\right) .{ }^{16}$ The effect of the inclusion of the MP spacer within the SAM is clearly demonstrated upon comparison of MPA/Cyt $c$ and MPA:MP/Cyt $c$ electrodes. The mixed monolayer electrode has an order of magnitude lower LOD and nearly a 5 -fold better sensitivity than a monolayer of MPA alone.

The SAM chemical structures of the DTSP/Cyt $c$ and MPA/ Cyt $c$ electrodes should be similar, but the former exhibited a lower LOD value and higher sensitivity toward SO than the latter, which may be related to better assembly of DTSP on the gold surface and its higher efficiency for the amide reaction with Cyt $c$. The sensitivity of the DTSP/Cyt $c$ electrode $\left(410 \mathrm{nA} \mu \mathrm{M}^{-1}\right.$ $\mathrm{cm}^{-2}$ ) is more than 2 times greater than MPA/Cyt $c$ value and it is almost 5 times greater than the value for the commonly used MUA:MU/Cyt $c$ electrode. This sensitivity is similar to that of a multilayer (layer-by-layer technique with 6 layers) Cyt $c$ sensor made on a gold wire $\left(398 \mathrm{nA} \mu \mathrm{M}^{-1} \mathrm{~cm}^{-2}\right){ }^{29}$

Analysis of Transport Limitations in SO Detection. In order to understand the effect of the mass-transfer rate of SO to the electrode surface on the amperometric response of the enzymatic electrodes, current responses were measured as a function of

(28) Gonzalez, A. G.; Herrador, M. A. TrAC-Trends Anal. Chem. 2007, 26, 227238. 


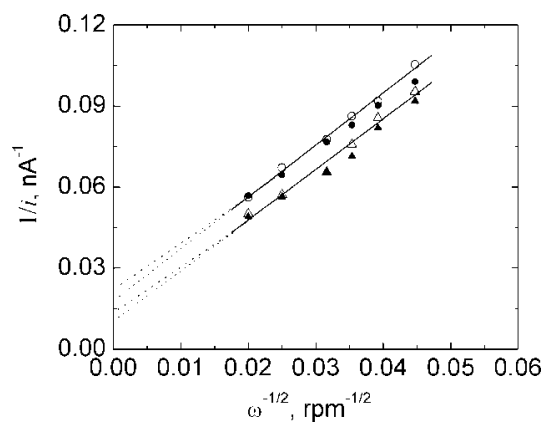

Figure 5. Levich-Koutecky plots of the MP monolayer and MPA: MP/Cyt $c$ electrodes at various applied potentials (SO was generated by $20 \mathrm{mU} / \mathrm{mL}$ XOD and $200 \mu \mathrm{M}$ xanthine). MP monolayer electrode at $+200 \mathrm{mV}(\Delta)$, MPA:MP/Cyt $c$ electrode at $+200 \mathrm{mV}(\boldsymbol{\Delta})$, MP monolayer electrode at $+150 \mathrm{mV}(\mathrm{O})$, and MPA:MP/Cyt $c$ electrode at $+150 \mathrm{mV}(\bullet)$.

rotation speed at potentials of 150 and $200 \mathrm{mV}$ for the neat MP monolayer electrode and the MPA:MP/Cyt $c$ electrode, which are the two systems with the highest sensitivity values (Table 1). Results are shown in Figure 5 in the form of a Levich-Koutecky plot. The curves show that mass transfer plays an important role in the operation of the biosensors. Furthermore, the slopes of the four lines are nearly the same, as would be expected if the reaction rate is limited by mass transfer of SO to the surface. ${ }^{30}$

The Levich-Koutecky equation takes the form of

$$
\frac{1}{i}=\frac{1}{i_{K}}+\frac{1}{0.62 n F A D_{O_{2}^{-}}^{23} \omega^{12} v^{-16} C_{O_{2}^{-}}}
$$

where all parameters are defined in the Supporting Information. All parameters are known in the second term of the right-hand side of eq 5, except the diffusion coefficient and the bulk concentration of SO. Assuming that the diffusion coefficient of $\mathrm{SO}$ is the same as the measured value for dioxygen in water, $D_{\mathrm{O}_{2}}{ }^{--}$ $=2 \times 10^{-5} \mathrm{~cm}^{2} \mathrm{~s}^{-1}$, the bulk concentration $\mathrm{C}_{\mathrm{O}_{2}}{ }^{-}$can be estimated from the slope of each curve. In the presence of $20 \mathrm{mU} / \mathrm{mL} \mathrm{XOD}$ and $200 \mu \mathrm{M}$ xanthine, values of 0.24 and $0.25 \mu \mathrm{M}$ were found at +150 and $+200 \mathrm{mV}$ for the MP monolayer electrode, respectively. These values are in good agreement with the SO concentration $(0.31 \mu \mathrm{M})$ determined by the UV spectrophotometric method shown in Figure 1B.

Amperometric Responses to SO Radical in Culture Media. Figure 6 shows the amperometric responses of selected electrodes (MP, MPA/Cyt $c$, MUA:MU/Cyt $c$, and DTSP/Cyt $c$ ) to SO in fresh MEM with and without $10 \%$ fetal bovine serum (FBS). The amperometric response of MP electrode to $0.53 \mu \mathrm{M}$ SO in MEM is $15.5 \mathrm{nA}$, which is a $50 \%$ decrease in the response to the same amount of SO in $25 \mathrm{mM}$ PB as shown in Figure 1B. In contrast to the MP electrode, the Cyt $c$ electrodes (MPA/Cyt $c$, MUA:MU/ Cyt $c$, and DTSP/Cyt $c$ electrodes) have similar amperometric responses to SO both in MEM and phosphate buffer.

The amperometric responses of all electrodes are negligible in fresh MEM with the addition of $10 \% \mathrm{FBS}$, indicating that the FBS fouls the electrode surface for the electrochemical detection

(29) Beissenhirtz, M. K.; Scheller, F. W.; Lisdat, F. Anal. Chem. 2004, 76, 46654671.

(30) Bard, A. J.; Faulkner, L. R. Electrochemical Methods: Fundamentals and Applications; John Wiley \& Sons, Inc.:New York, 2001.
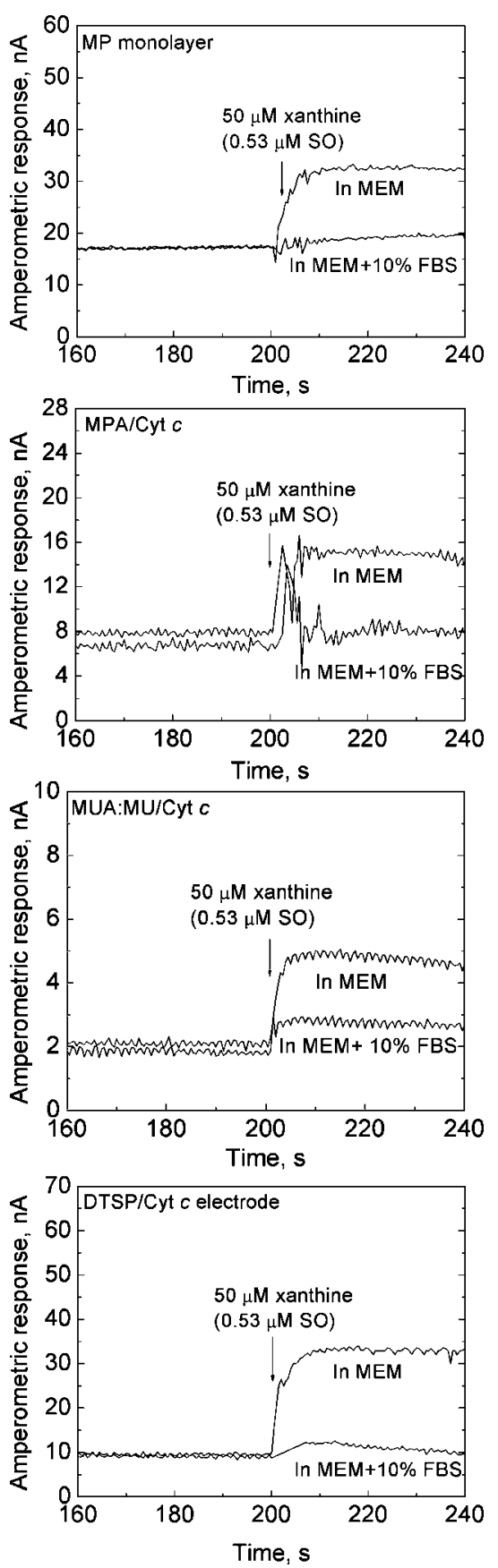

Figure 6. Responses of the monolayer electrodes and Cyt $c$ modified electrodes to SO in fresh MEM with and without FBS at an applied potential of $+200 \mathrm{mV}$ vs $\mathrm{Ag} / \mathrm{AgCl}$ reference. All reactions were performed with $60 \mathrm{mU} / \mathrm{mL}$ XOD.

of SO. The proteins in FBS may nonspecifically adsorb on the electrode surface, blocking access of the SO to the Cyt $c$ and gold electrode, leading to this degraded response.

To further understand the responses of the electrodes, the effects of other interferents were also explored. Figure 7 shows the comparison of the amperometric responses of four different electrode configurations to $0.1 \mathrm{mM} \mathrm{H}_{2} \mathrm{O}_{2}, 20 \mu \mathrm{M}$ ascorbic acid, $0.53 \mu \mathrm{M}$ SO in $\mathrm{PB}$, and $0.53 \mu \mathrm{M}$ SO in fresh MEM. The MP electrode has the highest response to SO in PB, while the DTSP/ Cyt $c$ electrode is the most sensitive to SO in fresh MEM. In fact, both the MPA/Cyt $c$ and DTSP/Cyt $c$ electrodes were more 


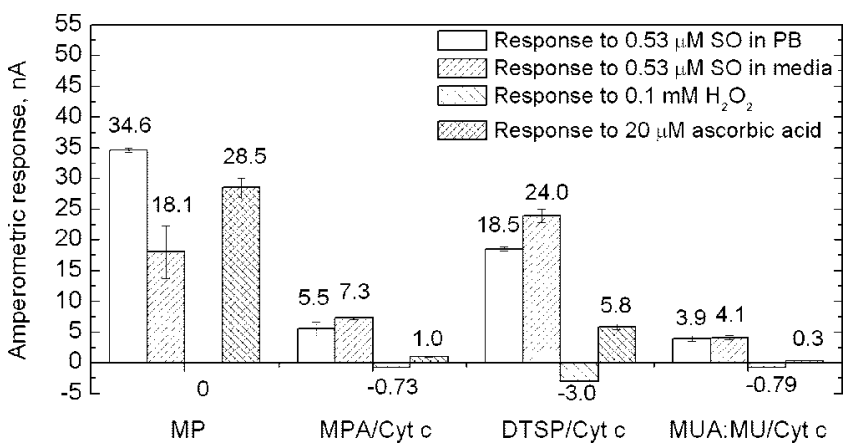

Figure 7. Comparison of the responses of four electrodes to $\mathrm{H}_{2} \mathrm{O}_{2}$, ascorbic acid, SO in PB, and SO in MEM. The steady-state concentration of SO was generated by $60 \mathrm{mU} / \mathrm{mL}$ XOD and $50 \mu \mathrm{M}$ xanthine, which results in a concentration of $0.53 \mu \mathrm{M}$.

sensitive to SO in MEM than in PB. The results in Table 1 indicate that the MP monolayer electrode may be the best for the detection of $\mathrm{SO}$ in $\mathrm{PB}$ without interferents, but it has a very strong response to ascorbic acid, and its response to SO in fresh MEM drops by almost $50 \%$ of the value in phosphate buffer. Conversely, the Cyt $c$ electrodes show better selectivity than the monolayer electrode in more physiologically relevant environments, such as culture media. As discussed before, the DTSP/Cyt $c$ and MPA/Cyt $c$ electrodes should be structurally similar, but the results in Figure 7 show that the DTSP/Cyt $c$ electrode is more sensitive to every condition examined as compared to the MPA-based electrode. This is especially clear for the $\mathrm{H}_{2} \mathrm{O}_{2}$ results, as it is known that immobilized Cyt $c$ can exhibit pseudoperoxidase activity. ${ }^{16}$ The increased sensitivity to $\mathrm{H}_{2} \mathrm{O}_{2}$ suggests that the DTSP monolayer enables an increase in Cyt $c$ activity or coverage on the electrode surface.

The DTSP/Cyt $c$ electrode appears to offer the best tradeoff between current response and specificity. Therefore, a calibration curve for this electrode configuration was made in MEM media (Figure 8). However, when designing an analytical device that will operate in tissue culture media, ${ }^{17,31,32}$ it may be difficult to obtain a good background signal due to the presence of interferents concurrently produced with the SO by cells. Therefore, the calibration curve in MEM was created using two different methods. In method I (Figure 8A), the total resulting current was measured after the addition of XOD, just as was done for the calibration curves made in PB (Figure 4). In method II, a bolus of SOD enzyme was added after achieving a steady-state SO concentration, and the difference in the amperometric response before and after the SOD addition was measured. This may be a more relevant protocol for the measurement of SO concentrations in tissue culture samples, as it utilizes the specificity of the SOD enzyme combined with the high sensitivity of the DTSP/Cyt $c$ electrode. Calibration curves for the two methods are shown in Figure 8B, and the sensitivities for these curves are shown in Table 2. Remarkably, the sensitivity of the DTSP/Cyt $c$ electrode in MEM, using either method I or method II, is higher than was observed in PB. The sensitivity using method II $\left(740 \mathrm{nA} / \mu \mathrm{M} / \mathrm{cm}^{2}\right)$ is 3 times higher than what was recently reported for engineered

(31) Viravaidya, K.; Sin, A.; Shuler, M. L. Biotechnol. Prog. 2004, 20, 316-323.

(32) McAuliffe, G. J.; Chang, J. Y.; Glahn, R. P.; Shuler, M. L. Mol. Cell. Biomech. 2008, 5, 119-132.
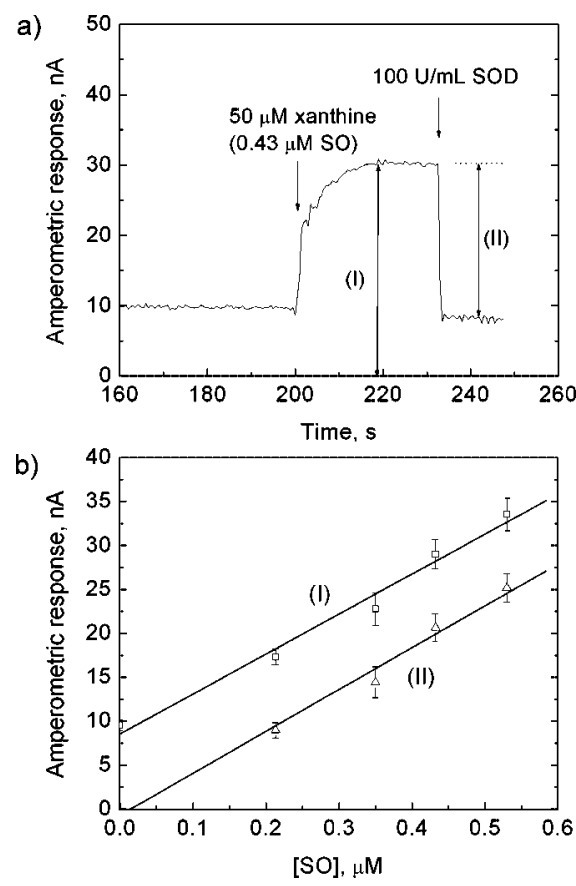

Figure 8. (A) Amperometric response of the DTSP/Cyt $c$ electrode to SO in MEM media; (B) Calibration curves of 3 different DTSP/Cyt $c$ electrodes to SO in MEM at $+200 \mathrm{mV}$ vs $\mathrm{Ag} / \mathrm{AgCl}$ reference (response of the electrodes upon the addition of $50 \mu \mathrm{M}$ xanthine in the presence of XOD (method I, $\square$ ) and the current drop upon the addition of $100 \mathrm{U} / \mathrm{mL}$ SOD (method II, $\Delta$ ).

\section{Table 2. Sensitivities of DTSP/Cyt $c$ Bioelectrodes in} Buffer and Cell Culture Media ${ }^{a}$

\begin{tabular}{|c|c|}
\hline experimental conditions & sensitivity $\left(\mathrm{nA} / \mu \mathrm{M} \cdot \mathrm{cm}^{2}\right)$ \\
\hline phosphate buffer & 410 \\
\hline MEM (method I) & 640 \\
\hline MEM (method II) & 740 \\
\hline
\end{tabular}

SOD that is directly immobilized on a gold wire $\left(230 \mathrm{nA} \mu \mathrm{M}^{-1}\right.$ $\left.\mathrm{cm}^{-2}\right){ }^{24}$ This shows that the specificity of the SOD enzyme can be combined with the high sensitivity of the Cyt $c$ electrodes to create high-performance systems for SO detection.

\section{CONCLUSIONS}

The amperometric responses of monolayer electrodes and Cyt $c$-modified electrodes to SO were systematically investigated. The responses of the monolayer electrodes to SO strongly depend on the functional termini of the monolayers. SO is easily electrochemically oxidized on the monolayer electrodes with amino or hydroxyl terminals, while the monolayers with methyl or carboxyl terminals seem to block the access of SO to the gold electrode. Although the MP monolayer electrode shows high sensitivity and low LOD for SO detection in $\mathrm{PB}$, the Cyt $c$ electrodes exhibit higher selectivity and better resistance to fouling in culture media. The DTSP monolayer is a better electron relay than the MPA monolayer after immobilization of Cyt $c$. As a result, the DTSP/Cyt $c$ has the best sensitivity to SO among the Cyt $c$ electrodes in both $\mathrm{PB}$ and MEM. Moreover, the DTSP/Cyt $c$ electrode is likely to be the 
most suitable electrode among all of the investigated electrodes for SO detection in terms of the trade-offs with sensitivity, selectivity, and LOD. By operating the electrode before and after the addition of the SOD enzyme, the high sensitivity of the Cyt $c$ system can be combined with the selectivity of the SOD enzyme to create an optimal configuration for monitoring SO concentrations in physiological environments.

\section{ACKNOWLEDGMENT}

This research was supported by the U.S. Army Applied Research Program. We thank Lt. Col. Robert Bozic for helpful discussions and assistance.

\section{SUPPORTING INFORMATION AVAILABLE}

Additional information as noted in text. This material is available free of charge via the Internet at http://pubs.acs. org.

Received for review April 21, 2008. Accepted October 11, 2008.

AC800796B 
Supplementary Information

\title{
Detection of the superoxide radical anion using various alkanethiol monolayers and immobilized cytochrome $c$
}

\author{
Xiaojun J. Chen ${ }^{\dagger, \ddagger} \S$, Alan C. West ${ }^{\dagger}$, Donald M. Cropek ${ }^{\ddagger}$, and Scott Banta ${ }^{\dagger, *}$
}

Department of Chemical Engineering, Columbia University, New York, New York

U.S. Army Engineer Research and Development Center, Construction Engineering Research Laboratory (CERL), Champaign, Illinois 


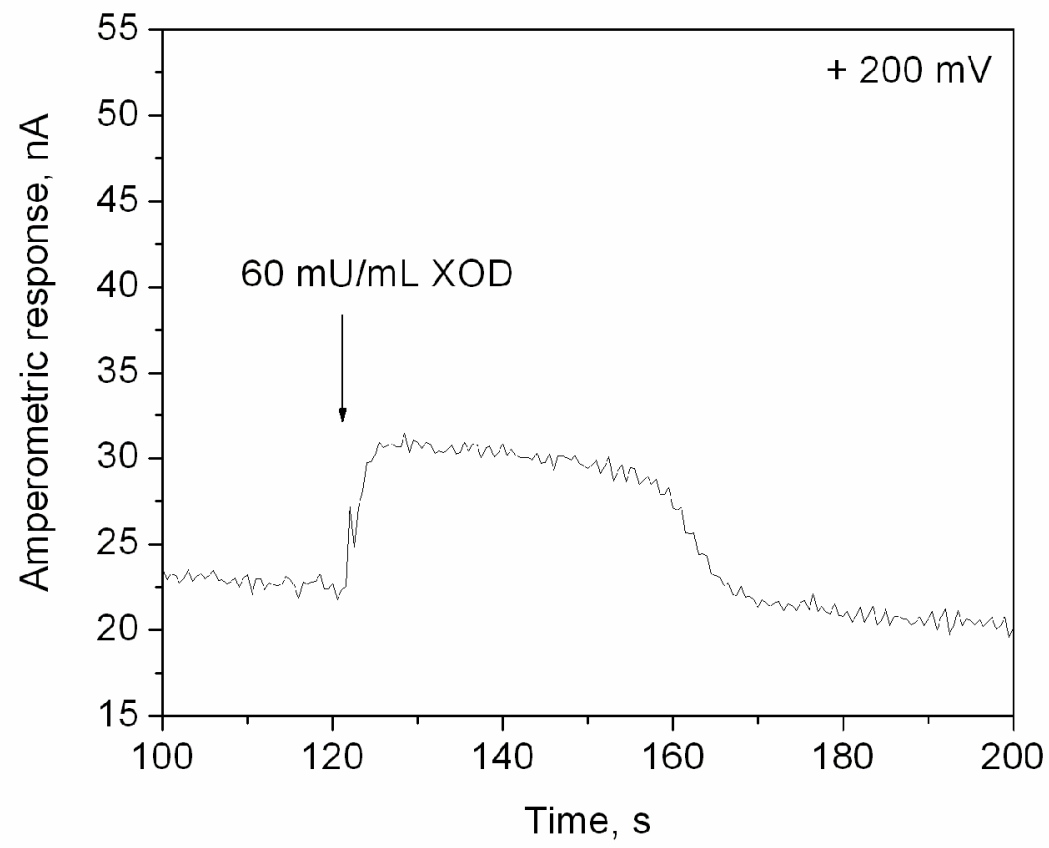

Figure 1. Response of a bare gold electrode to $\mathrm{SO}$ generated by $60 \mathrm{mU} / \mathrm{mL}$ XOD and $50 \mu \mathrm{M}$ xanthine at $+200 \mathrm{mV}$. 


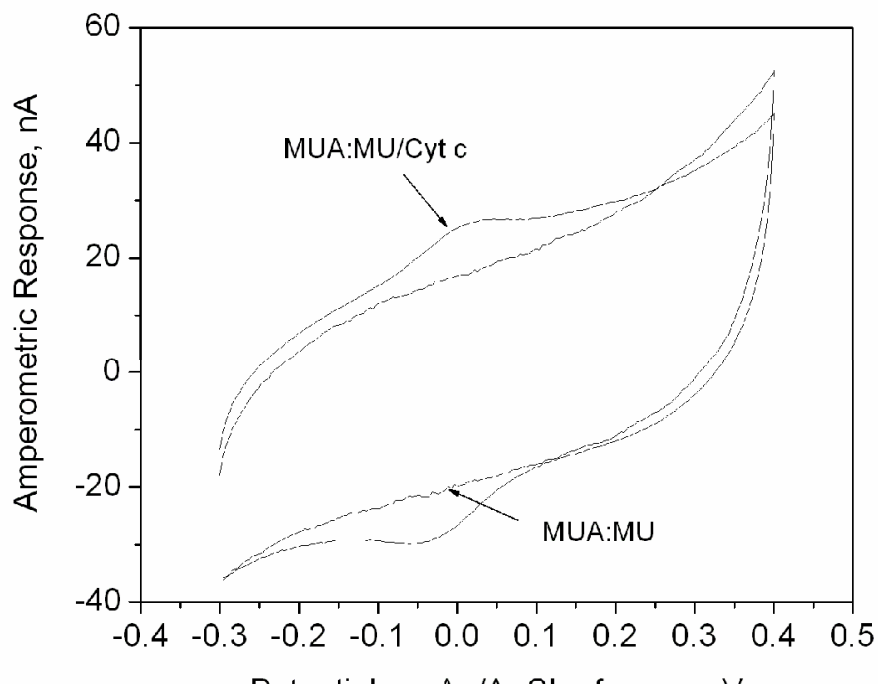

Potential vs. $\mathrm{Ag} / \mathrm{AgCl}$ reference, $\mathrm{V}$

(A)

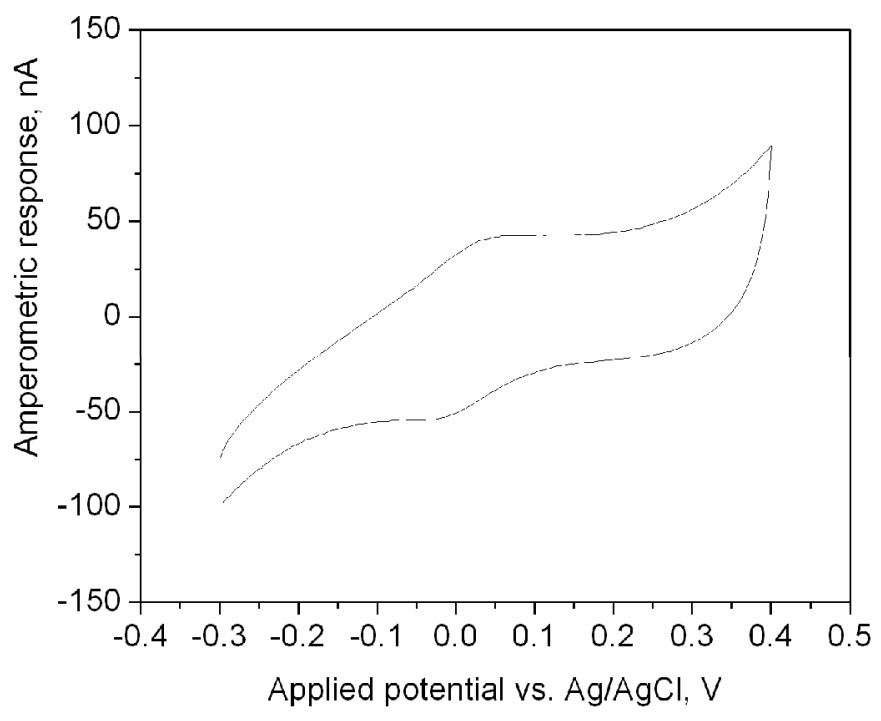

(B) 


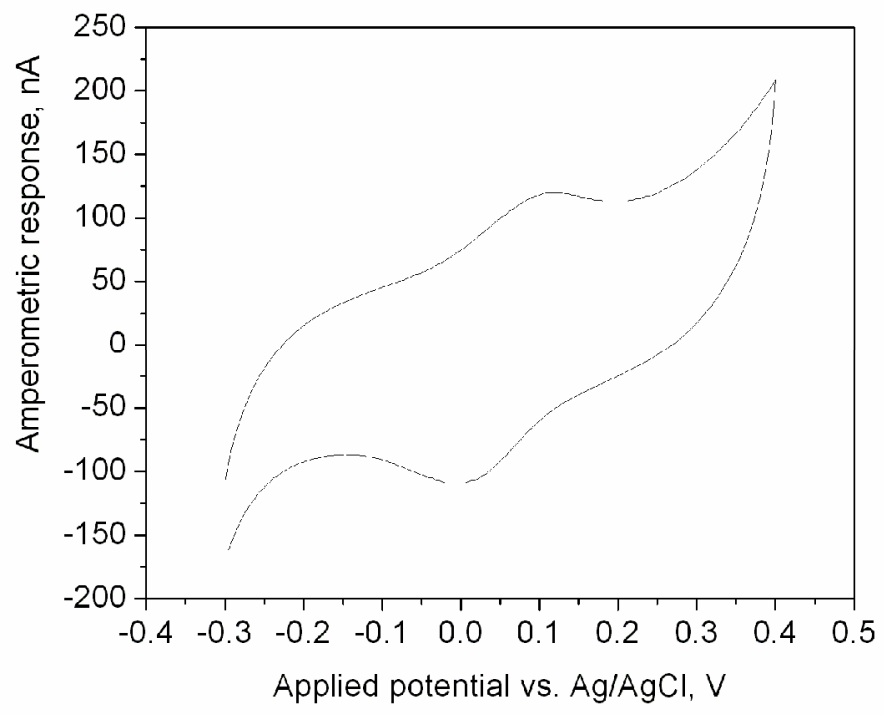

(C)

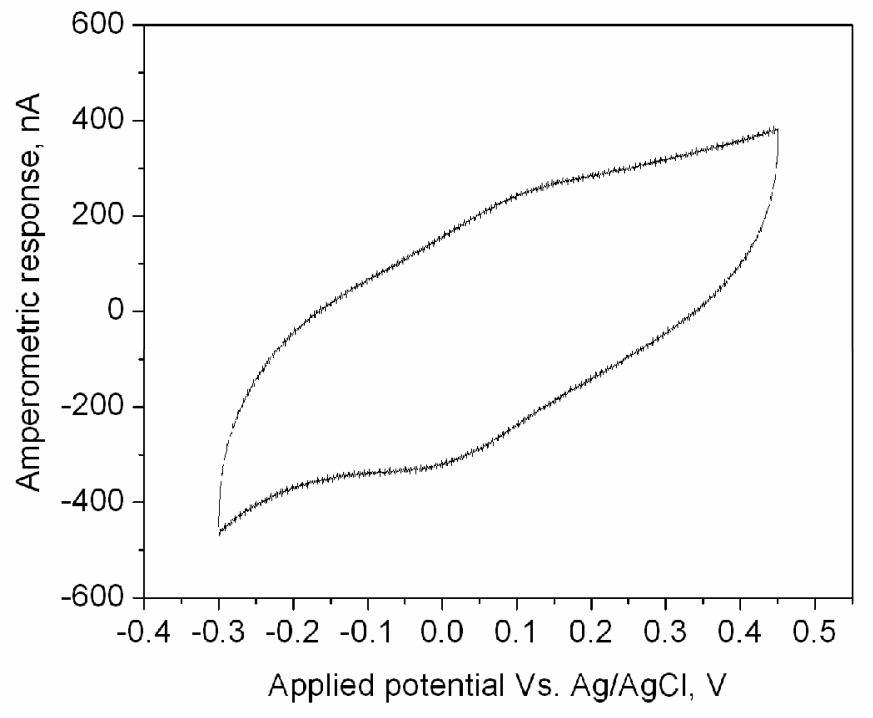

(D)

Figure 2. Cyclic voltammograms of Cyt $c$ electrodes with a scan rate of $50 \mathrm{mV} / \mathrm{s}$. (A) MUA:MU/Cyt $c$ monolayer compared to a neat MUA:MU monolayer. (B) MPA/Cyt $c$ monolayer. (C) MPA:MP/Cyt $c$ monolayer. (D) DTSP/Cyt $c$ monolayer. 


\section{LIST OF SYMBOLS}

n

number of electrons involved for the electron transfer reaction

$\mathrm{F}$

Faradaic constant $\left(96,485 \mathrm{C} \mathrm{mol}^{-1}\right)$

$C_{O_{2}^{--}}$

Bulk concentration of $\mathrm{O}_{2}{ }^{--}\left(\mathrm{mol} \mathrm{cm}{ }^{-3}\right)$

$D_{O_{2}^{--}}$

Diffusion coefficient of $\mathrm{O}_{2}{ }^{--}\left(\mathrm{cm}^{2} \mathrm{~s}^{-1}\right)$

A

Surface area of the electrode $\left(\mathrm{cm}^{2}\right)$

$\mathrm{i}_{\mathrm{k}}$

the current in the absence of any mass transfer effects $\left(\mathrm{A} \mathrm{cm}^{-2}\right)$

$v$

Kinematic viscosity $\left(\mathrm{cm}^{2} \mathrm{~s}^{-1}\right)$

$\omega$

Angular velocity (rpm or radians per second) 